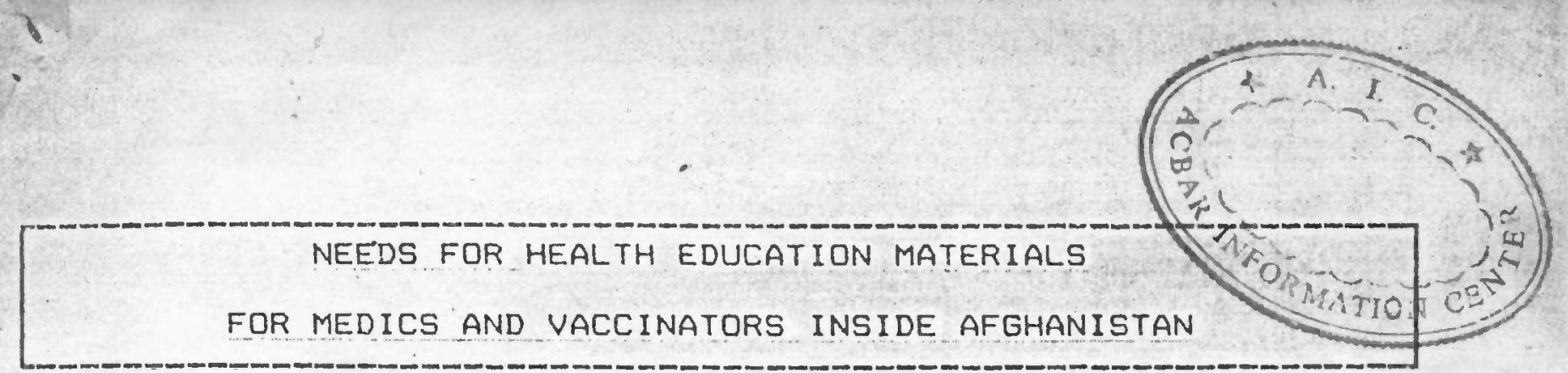

Dr. Eernard Faliu

$$
\text { AVICE.N + I.M.C. }+ \text { C.M.C }
$$

A report. written for presentation to the UNHCR Health Education Teaching Material Workshop - August 88.

This report was developed based on information from the CMC monitoring questionnaire of health facilities in Afghanistan.

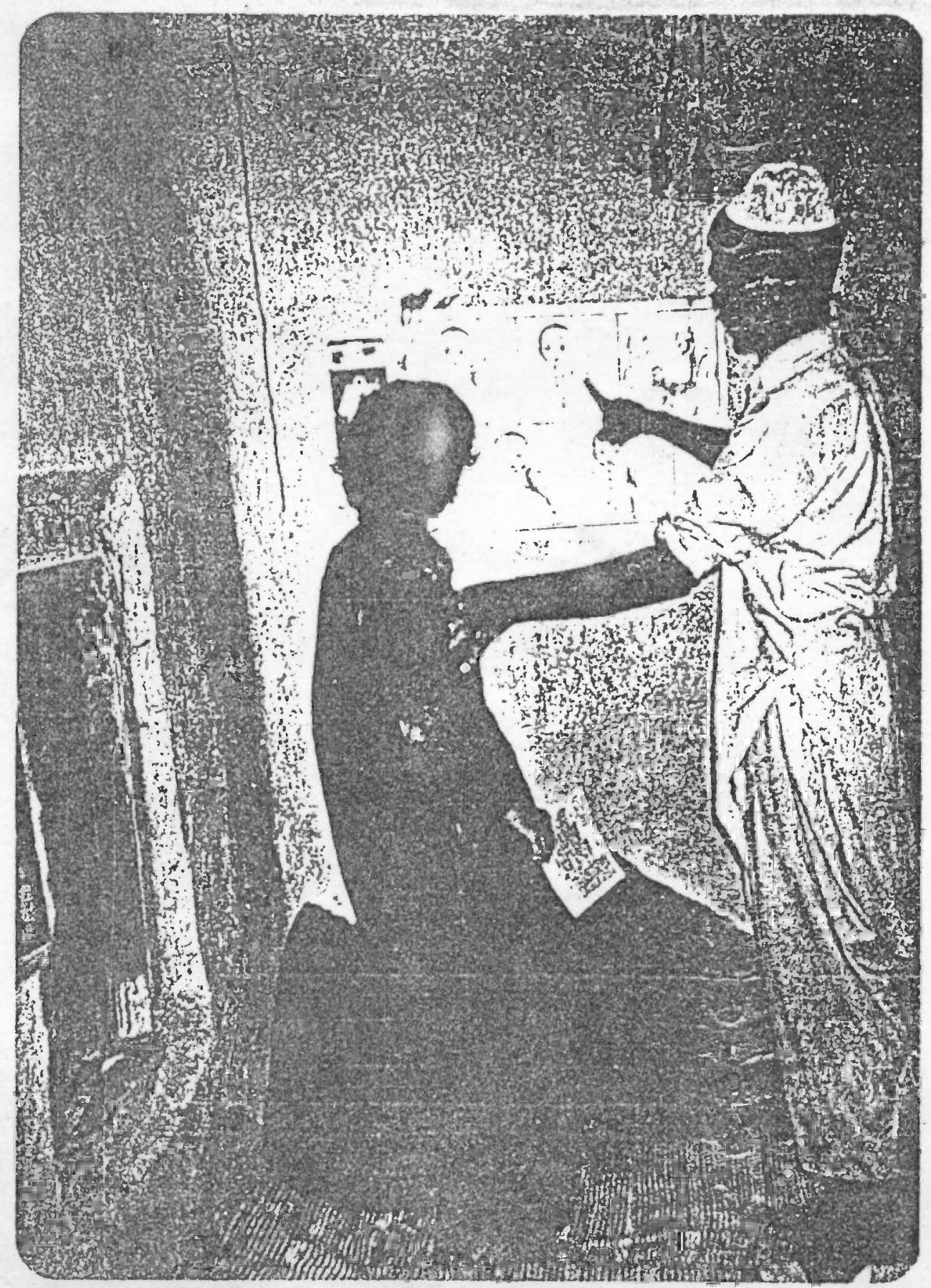

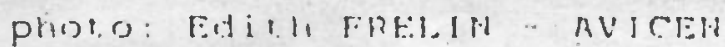


Bernard Faliu M.D 27/08/88 (AVICEN, IMC, CMC)

NEEDS FOR HEALTH EDUCATION MATERIALS

FOR MEDICS AND VACCINATORS INSIDE AFGHANISTAN

From June 30,1988 to August 15, 1988, an IMC team went into Afghanistan. The aim of the mission was an evaluation of a vaccination pilot programme in LOGAR (AVICEN vaccinators working adjacent to an IMC clinic) as well as the monitoring of 6 IMC clinics.

Composition of the evaluation mission team:

1 IMC Afghan monitor

1 IMC translator

1 French M.D specialized in public health

\section{THE VACCINATION PILOT PROJECT}

The poster issued by UNICEF about BCG side effects ( 5 pictures) was used to advertize vaccinations in each village. It was explained to the community by the vaccinators and left on the outside wall of house or mosque where the immunization session was going to take place. It served as a sign or a flag advertizing immunizations.

The vaccinators had 7 of these posters when they left Peshawar, but after 2 months all these posters disappeared or were torn by children who liked these posters too much. Silk screen or cloth posters would be better to avoid being torn by children playing or getting dirty during the trip.

To advertize immunizations of E.P.I, the 6 photo poster about target diseases could be very helpful. However we found it only in English or in French. This kind of poster can be found in AVICEN but not in large quantity. Because of the limited numbers, they are used only as teaching material for vaccinator training (with the WHO/EPI slides on target diseases).

We were shown a few days ago a draft of a poster (with drawings) inspired by the 6 target diseases poster. On this draft, made by HERC (IRC), the photos were changed to pictures more culturally acceptable (afghan clothes and caps) and the text was written in pashtou. Even if the target population cannot recognize at first the 6 diseases (for diphteria or T.B) this poster can be used by the medic or health educator to explain the community which diseases can be prevented by E.P.I.

The main problem inside Afghanistan is not to advertize immunizations for children. People like injections too much (and always ask the medics for injections). When vaccinators arrived in a village in LOGAR they were very popular because they were going to give an injection to each kid. The problem which needs 
to be addressed is the difficulty in gaining acceptance of immunization for women to prevent neonatal tetanus.

In LOGAR, as we were checking immunization cards in the villages already immunized, a short survey asking questions of 70 families was conducted (see appendix 1). Results from the poll revealed that $1 / 3$ of the children who died prior to 5 years of age, died in the first or second week of life. Based on epidemiological surveys conducted in other developing world countries, one can assume that approximately $50 \%$ of these deaths can be imputed to neonatal tetanus.

In trying to overcome resistance to female vaccination two points should be appreciated.

First, there are not yet any fixed immunization centers in resistance-held Afghanistan, and mobile teams can be composed only of males (women are not allowed to go and work far from their family).

Second, a woman is most often not allowed to be immunized by a male vaccinator. This seems to be more linked to local customs (still strong in rural Afghanistan) rather than to Islamic rule.

In the district of LOGAR where we went, some villages refused completely immunization for women. The men asked the vaccinators for vaccines, needles and syringes, saying they wanted to immunize their wifes themselves. The vaccinators refused, saying that if local customs didn't allow a woman to be immunized by a male vaccinator, the immunization center AVICEN didn't allow the vaccinators to give vaccines and needles to the husbands to perform themselves immunizations.

A point that is worthy of addressing in future training for vaccinators is to be more assertive. Vaccinators realized that advertizing tetanus toxoid immunizations for women was difficult. We never saw them insisting when the men or the mullahs were saying that immunizations are useless for their wifes. However on the last day of immunization supervision, we were tired of being only observers. So when we saw some women bringing children to the immunization session (usually this role is devoted to the father in LOGAR) we asked the vaccinators to insist to register and immunize the mother just after the child. Most of these women accepted. We even saw some of the ones who refused in the morning coming back to the immunization session in the afternoon after having changed their minds.

We found that in the villages where there is a medic or a clinic (or in the village where the medic lives) women came more easily, probably because the community has had the need for, and the advantages of vaccination explained by a medic (belonging to their area who was able to find the right arguments). 


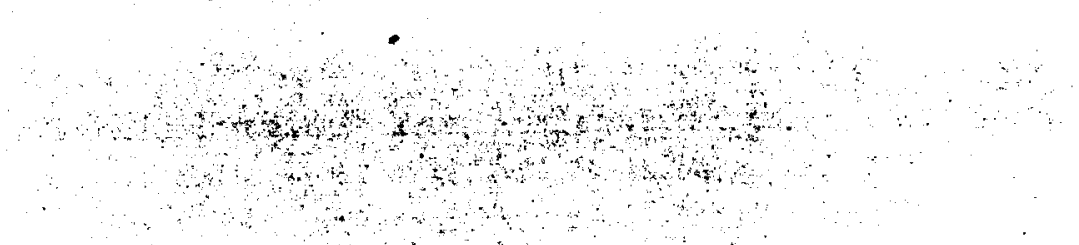

In conclusion we think the male vaccinator needs to be helped or encouraged to insist that the women attend the immunization session:

vaccinators won $t$ always have an expatriate with them to push them to insist for them

vaccinators won't always be helped by a medic to advertize tetanus immunization.

To help achieve this end, we think posters would be of great use: First, they will assist vaccinators to advertize tetanus immunization for women (even if they are shy or not interested in this kind of teaching material). They will also encourage the community to ask questions and to have the poster explained by the vaccinators.

Second, a poster with a drawing of a baby suffering from tetanus and unable to suck will remind parents about the death of a lot of their babies, and will make people sensitive to the immunization.

The only posters we found in Peshawar about prevention of neonatal tetanus are:
1) A poster in farsi and pashtou made by SERVE (in its health education set), explaining with drawings alone the different preventive strategies such as immunization and sterile material used to cut the umbilical cord (see appendix 2).

This poster is rather good and as IRC gave 5 of these to AVICEN, we will give this poster to our 5 next vaccination teams who go in-country and ask them to test them.

2) 2 posters in urdu produced by UNICEF (?):

one showing a baby with the whole body tensed

the other one with two pictures showing:

a pregnant woman being immunized

three women supposed to be of different ages being immunized ( see appendix 3 ).

But these posters don't seem to fit in afghan context:

- on the poster the vaccine is given by a lady vaccinator, and currently there is no female vaccinator in rural areas of Afghanistan,

- the women seem to be from India or Pakistan and not from Afghanistan. They show the faces. The drawer should know that quite often in country male vaccinators vaccinate women wearing tchadri (or burka) and are only allowed to see their arm (for the injection).

If these posters were arranged to look more afghan, and translated in farsi and pashtou, it would be a great help for the afghans vaccinators working in Afghanistan. 


\section{CLINIC MONITORING AND HEALTH EDUCATION}

During our mission in Afghanistan we had the opportunity to visit 9 clinics (not only IMC clinics) in 4 different provinces : LOGAR, WARDACK, GHAZNI, KABOUL and interview 16 medics.

To monitor the clinics we used a C.M.C questionnaire. Responses to these questions indicated that the medics had a poor appreciation of public health. Our feeling is that except for immunization programmes which are starting to be very successful now (with AVICEN), preventive or community medicine doesn't exist yet. A lot of efforts seem to have been made in the refugee camps in Pakistan but there is nearly nothing in Afghanistan.

To these questions we obtained the following responses:

PATIENT INSTRUCTION (Question 10.7): Does the medic take time to explain basic public health concepts such as the importance of clean water, sanitation, etc, when appropriate?

We saw only one clinic where one medic seemed to be interested by explaining these concepts to the patients, maybe because of the very high incidence of diarrhoea in this area during summertime.

In the other clinics health education seemed to be limited to:

"Wash your eyes when you have conjunctivitis"

"Boil water to mix with O.R.S or with salt and sugar when your baby has diarrhoea"

"Mix oil, milk and sugar to feed your baby because he is malnourished" (a medic completed 18 months of training)

2 medics said they had trained a traditional birth attendant.

Among the 9 clinics visited only 2 had latrines (that is not a good example). When we asked about latrines, most of the medics were laughing and saying that they had the largest latrine in the world. They showed us the fields around, the orchards, or some dry irrigation channels hidden by trees.

None of the latrines we saw had a covered pit. They were not ventilated by pipes. Flies seemed to enjoy these latrines. In one place where the bottom of the latrine was open, we had the surprise on discovering one morning as we were using it, that chickens were walking on the stools and pecking, looking for something to eat. We talked with our translator who was not surprised, and said such a thing is not uncommon. 
Although there seems to be little appreciation of the importance of sanitation, diarrhea is recognised as an important cause of illness by the medics. When we were asking them about the 3 main causes of death in their district, diarrhoea was noted to be a cause of infant and child mortality in 8 clinics. In

half the cases diarrhoea was given as the first cause. Again the connection between sanitation and diarrhea is not really made.

A short survey of 70 families was done. These families were asked if they had baby feeding bottles at home (see appendix 1). In the district visited in LOGAR $41 \%$ of the families seen had one baby bottle at home. People said that the women didnt't have enough milk to breast feed. In around $2 / 3$ of these families using bottles, the mother was still lactating a little bit. Cow or goat milk was said to be put in the bottle, nearly never mixed with water. The richest families said that they were buying powdered milk in the bazaar.

In TCHARK or in BARAKI RAJON Bazaars you can find easily baby bottles (Meiji baby-safe feeder, Camera, Canown, Mechicco) at a price varying from 120 to 180 Afghanis. Milk powder is sent in $450 \mathrm{gr}$ cans at the price of 280 Afghanis (instant KLIM, Nestle CERELAC, SnOw P7A).

Among children dying at an early age in these 70 families, we found the 2 main causes of death to be measles and diarrhoea. These 2 diseases caused $2 / 3$ of the deaths (see appendix 1 ).

That shows a need for posters explaining oral rehydration and advertizing measles immunization.

ADDITIONAL QUESTIONS (Question 17.5): Are there teaching materials in the clinic?

Only one of the 16 medics we met had some teaching material for patients. He had stuck on the inside wall, close to the place the patient waited to be checked, some pages (taken from a book, possibly " Where there is no Doctor" in pashtoul about health education. The text and the drawings of these pages were about signs of dehydration

Advice to pregnant women: food, rest ( 2 pages)

Transmission of T.B, and Testing sputum ( 2 pages)

Vaccinations.

This medic helped by Swedish Committee said he was not paid because he had been trained less than 6 months.

In the other clinics there were no posters on the walls except political posters or some pictures of Commanders who had died in Jihad, and calendars.

We think that posters about the dangers of baby bottles and advantages of breast feeding would be useful, as it is clear that feeding babies with bottles is a practice which is becoming more and more popular in this part of LOGAR. Some posters giving advice during pregnancy would also be of great help. 
We were shown some posters on breast feeding in Peshawar in SERVE office. Although generally good, we wondered about the following points. These posters show:

first a bottle fed baby who is very malnourished. However this baby is naked, and all the afghan babies we saw were tightly wrapped and wearing a conical and colourful cap. They were so tightly wrapped that it was always difficult to examine or vaccinate them.

secondly the breast fed baby is more healthy but we never saw an afghan small kid wearing such a yellow T-shirt and white pants.

This kind of poster would be of great interest, once made to look more like afghans so people could recognize themselves when they see the poster.

As we said before, 15 of the 16 medics we met inside didn't have any teaching material at all. At least half of them said that it was a lack and they would like to receive some and use it.

(Question 14.10): What is your biggest health problem?

(Question 14.14): Does the medic have any suggestions for future health care delivery and/or development in Afghanistan after the end of the war?

10 medics answered these questions.

In 7 cases they are complaining of shortage of medicine because they say the committees reduced the amount of medicines sent in-country. There is also a lack of T.B treatment.

Reducing the quantity of medicine can be a first step if medics teach patients how to use medicines. But only 4 medics said it was of paramount importance to train people in health care and to explain to them how to use medicines. When it was asked what was health care, these medics answered it was general information about health, and that the community needed to be taught how to use medicine, how to protect itself against diseases. These medics were particularly asking for some teaching material to fillful this aim.

Only one medic suggested that a water program had to be implemented (digging wells,...) to provide safe water to the community. 
Most of the other medics were asking for more equipment;

$X$-ray, lab, surgical facilities and means of transportation to refer patients.

9 medics wanted a modern hospital in their area.

\section{CONCLUSION}

Teaching material doesn't seem to exist in rural Afghanistan, except some pages taken from "Where there is no doctor" in pashtou, that we saw posted on the wall of one clinic.

As diarrhea has a high incidence in summer and causes deaths in babies and young children, it would be good to have posters about dehydration and oral rehydration, even if that is already explained briefly by medics working in country. We think the poster about rehydration produced by SERVE (in its health education set) for the refugee camps could be easily used inside Afghanistan.

There is a huge need of posters about latrines (how to build them and how to use them properly). But even if there is a lot of diarrhoeas it is going to be difficult: most of the medics who should be sensitive to this problem don't feel the need of such a thing.

Posters about how to use medicines would be useful. Committees could save medicines and patients could save money if they stop going to the bazaar to see a doctor who is charging them and prescribing the injections they demand.

Posters explaining the dangers of bottle feeding are needed urgently, together with posters advicing female food supplementation during pregnancy and lactating period. This kind of poster exists and only needs to be altered to better fit with the context of rural Afghanistan. Prolonged breast feeding with sudden introduction of foods all at once worsens diarrhea risk.

Actually any kind of teaching material for patients and for the community is going to be a great help in the next months or years inside Afghanistan

Last but not least posters advertizing immunizations, and especially posters focusing on overcoming resistance to female vaccination are needed. 
AVICEN = Afghanistan Vaccination and Immunization Center

IMC = International Medical Corps

CMC = Coordination of Medical Committees

IRC = International Rescue Committee

E.P.I = Expanded Programme on Immunization

O.R.S = Oral Rehydration Salt

H.E.R.C = Health, Education Resource Center

SERVE = Serving Emergency Relief and Vocational Entreprises

ACKNOWLEDGEMENTS to Kate Cita M.D, C.M.C Medical Director, who was kind enough to review the english style of this text.

\section{APPENDIX 1}

In the sub-district of LOGAR we worked, a short survey was made in 9 villages, reaching 70 families.

The following questions were asked to the head of the family (most of the time the father, only one woman, who was a widow answered.)

- How many children do you have in your family ?

- How many of your children have died ? (except during the first 15 days of life) ?

- What disease did they die from ?

- How many of your babies have died in the first or second week of life?

- Do you have baby bottle at home ? How many ? What do you put inside? Is the mother still breast feeding?

We recensed 287 children alife in these families

109 who had died: among them 31 died in the first or second week.

For the question "What disease did they die from ?" we had an answer only in 46 cases:

- 14 : diarrhea

- 12 : measles

- 7 : convulsions or meningitis

- 3 : pneumonia

- 10 : other diagnosis noted each once.

Maybe measles and diarrhea are overstated because they are easily recognizable. For example in one village during a measles epidemics a 2 days old baby who died was identified as having measles. Clearly in this case measles is not the cause of death, although it was the perceived cause of death.

Among these 70 families we retrieved 29 baby bottles (from 0 to 3 bottles depending on the family). 
P.S: In collaboration with H.E.R.C, AVICEN decided to make a poster advertizing Tetanus Immunization for women inside Afghanistan. This poster "Immunize pregnant women against tetanus" (see appendix 4-A) and another one "Immunize children against the 6 target diseases". (see appendix 5-A and 5-B) are going to be pretested in Afghanistan by AVICEN vaccination teams (see H.E.R.C. pre -testing forms : appendix 4-B and 5-C).

A new version has been made of this UNICEF poster about BCG side-effects. The third picture. has been removed because it was showing a kid with a dressing on the arm (after BCG injection), and that is no longer recommanded.

This poster could be used in refugees camps in Pakistan, but AVICEN and EPI-AR (Afghan Refugees) vaccinators objected that on this poster BCG is injected to the left arm (like AVICEN vaccinators do in Afghanistan) and that in Pakistan BCG is supposed to be injected to the right arm (following the E.P.IA. $R$ recommandations in NWFP.) 
APPENDIX 2

حاز زت عنتر

الف م- مان

أكين ضג

$-1$

J

تزريق يك هـ

ب - هركون

( )

1

كل نترازد وس

لـ وماه ضرور

براs

در رفاصله د

مكالم

$\therefore$ कि

د رعكيتن بالإن

$<+$

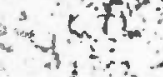

i

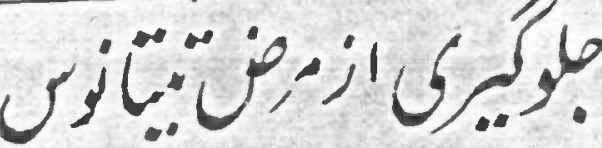
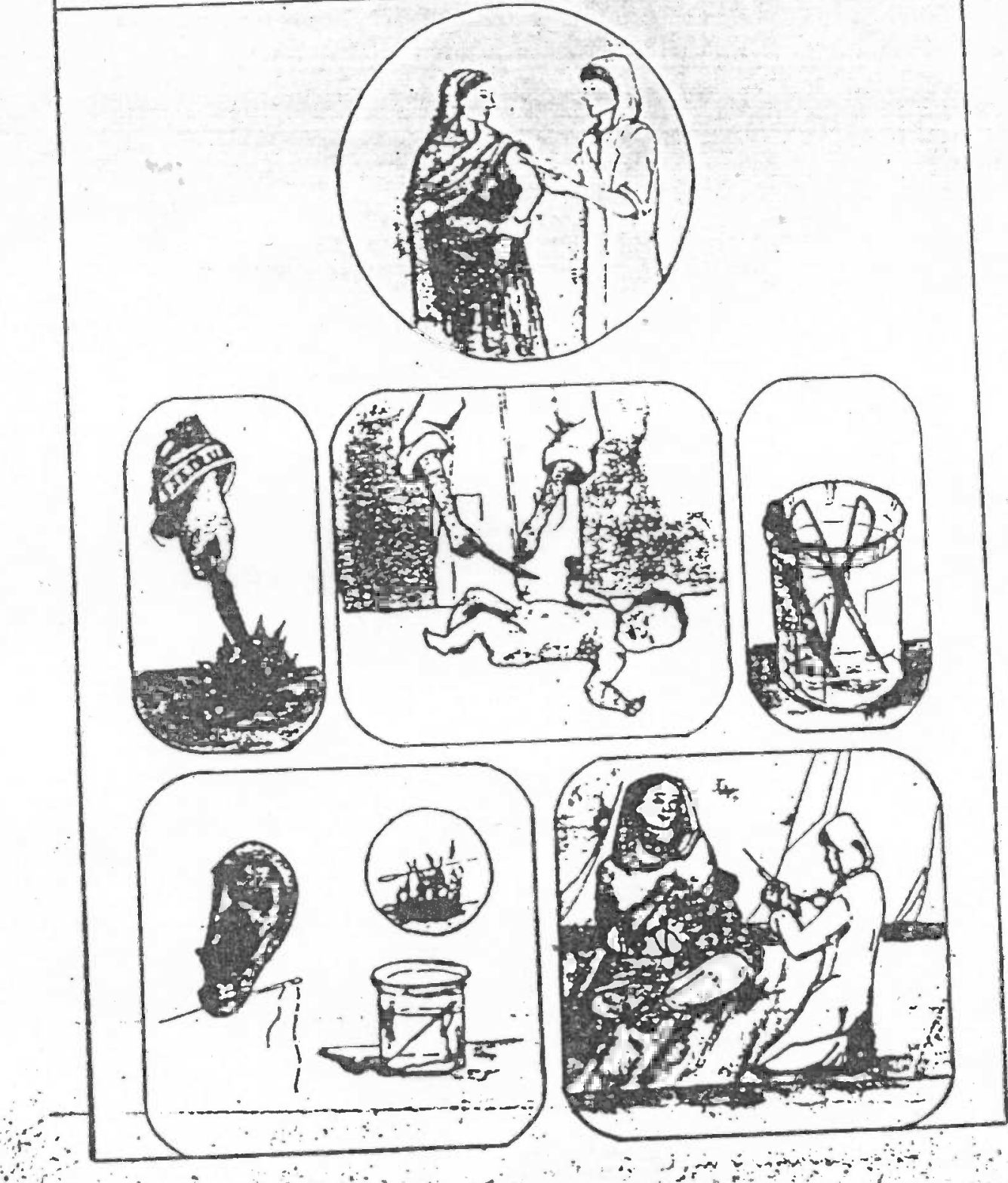
$\therefore$

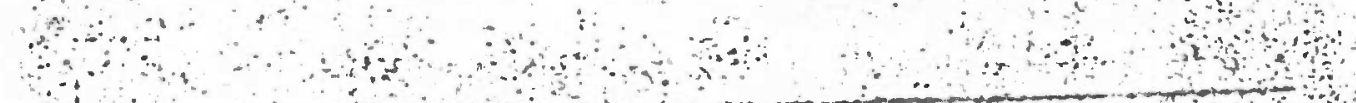




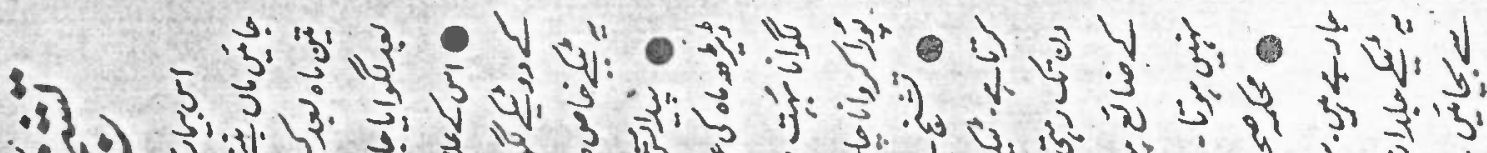

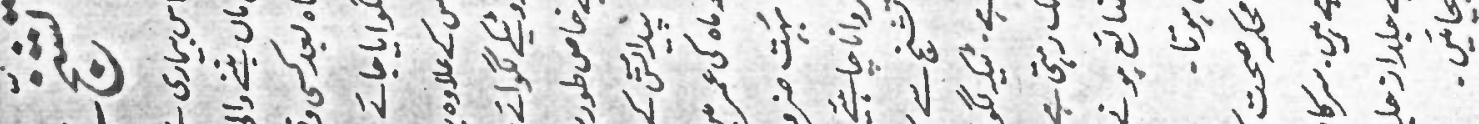

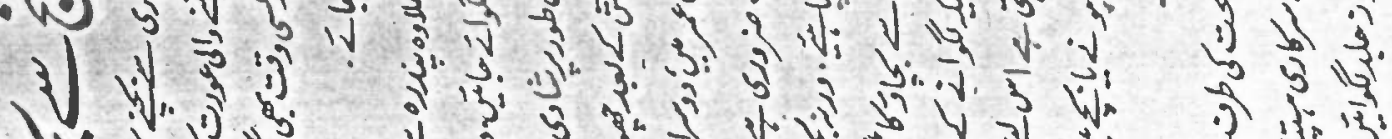

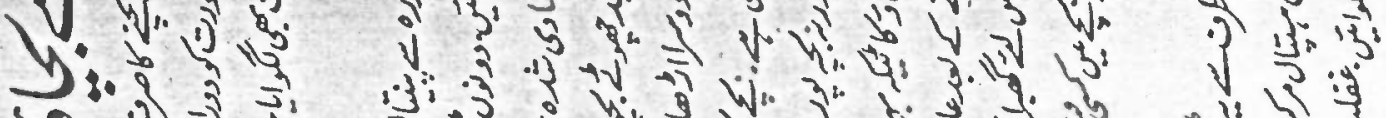

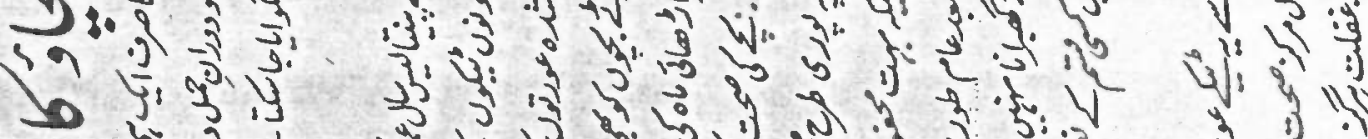

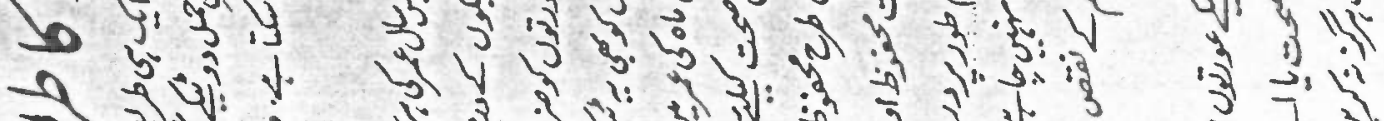

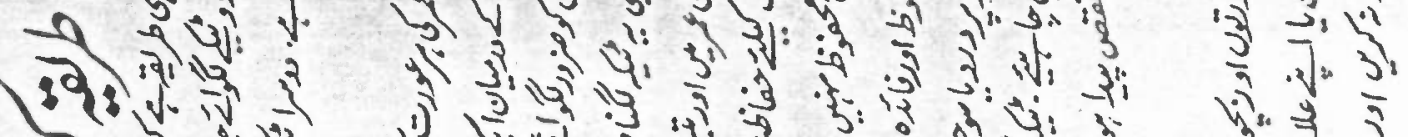

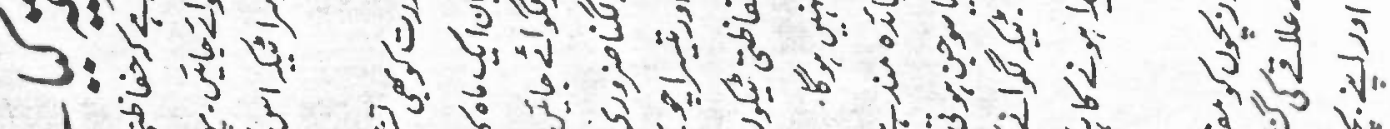
$\sqrt{4}$ औै

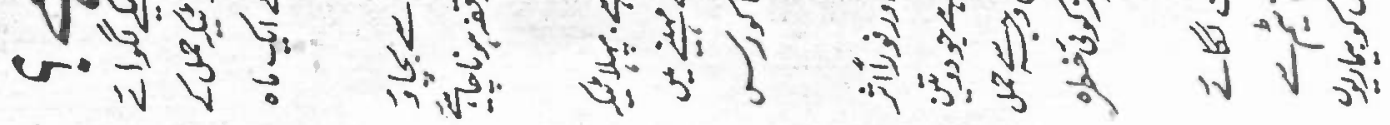
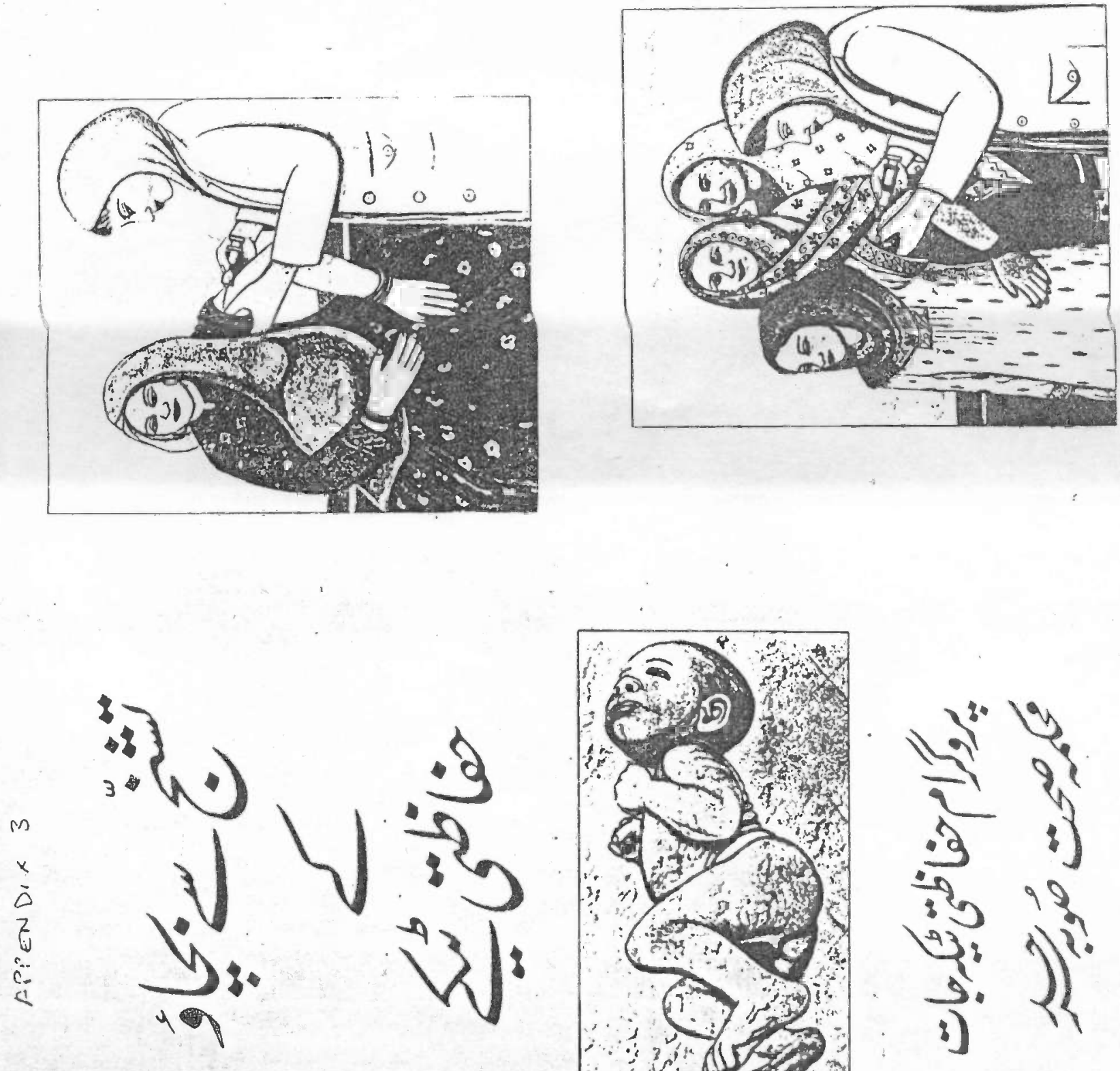

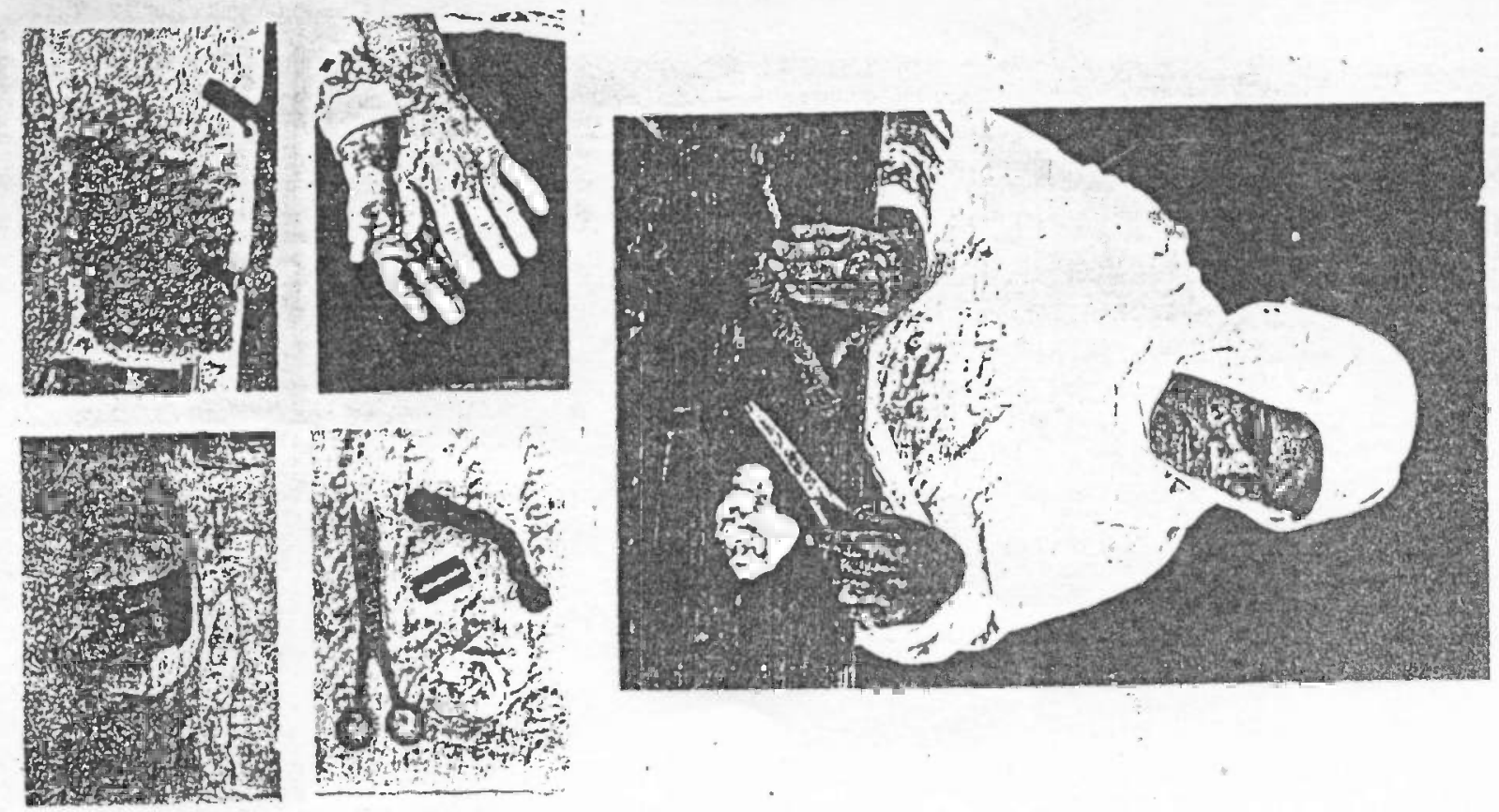

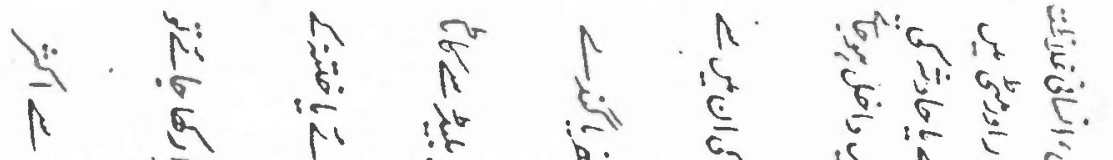

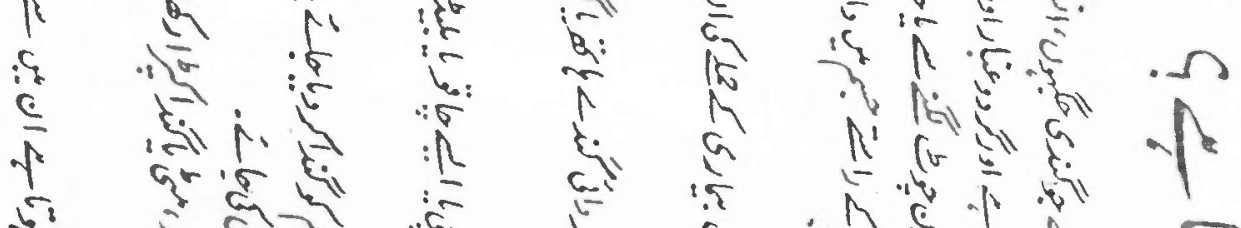

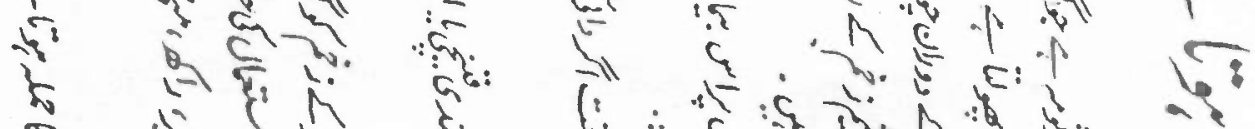

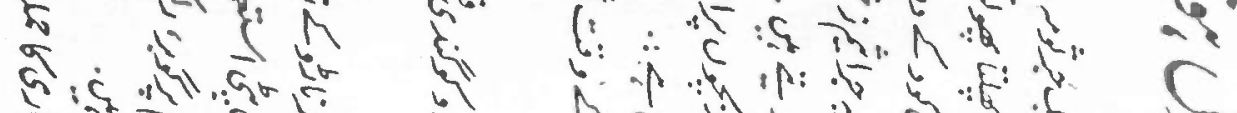

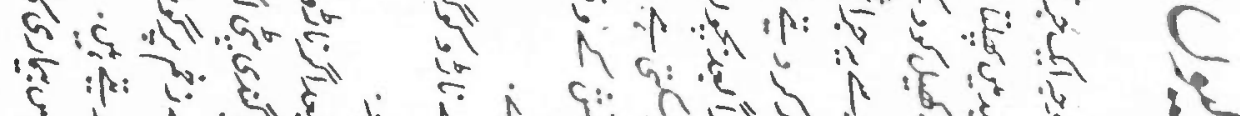

is 5 is

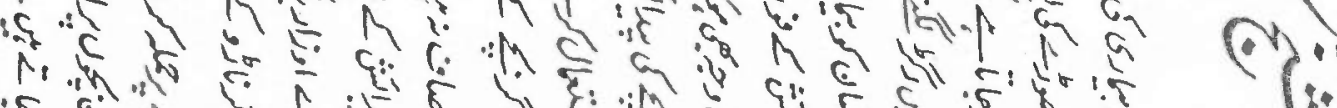

if

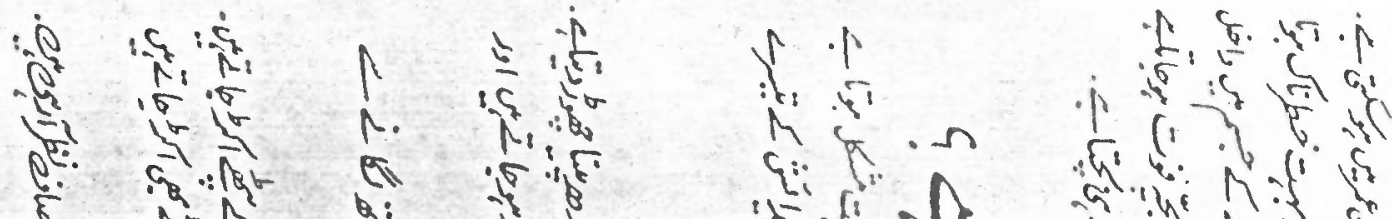

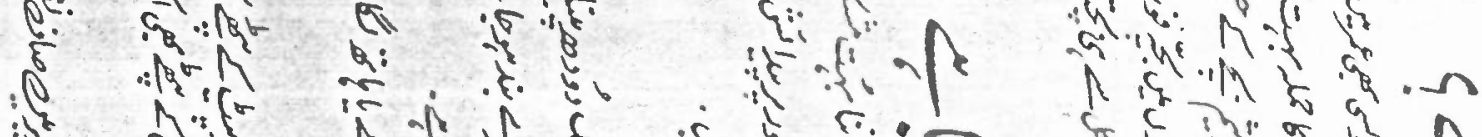

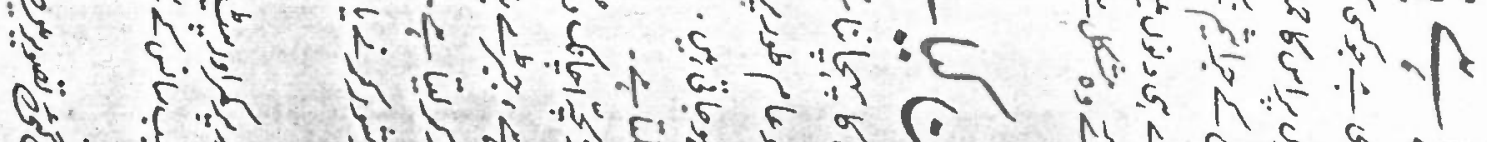

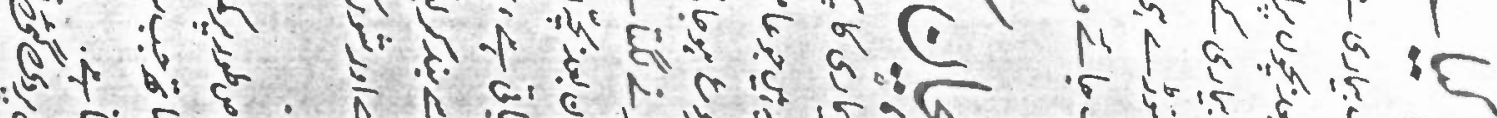

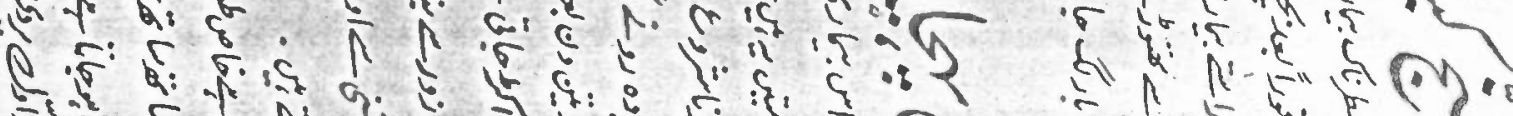
य. Q है. Q

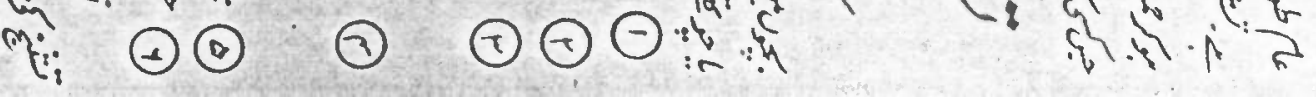



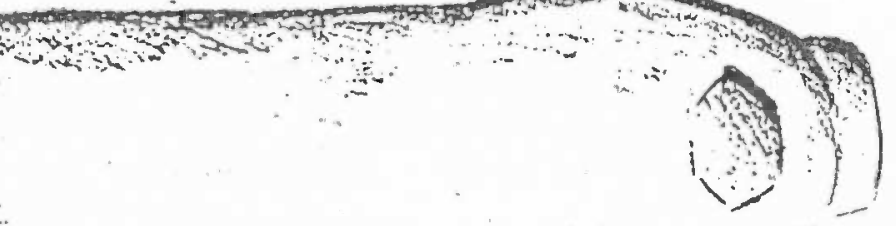

$\therefore$,
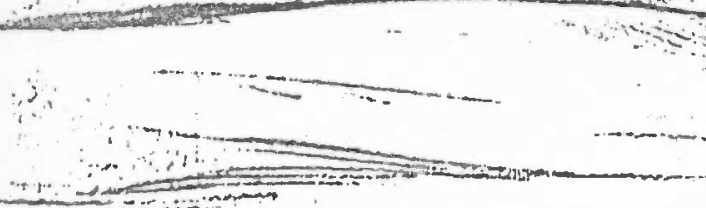

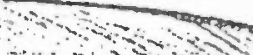

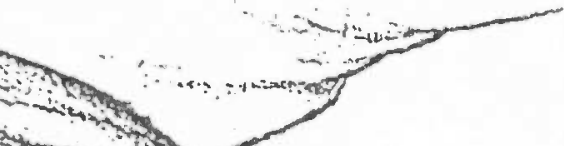

.............
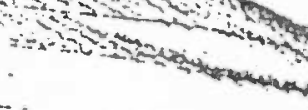

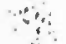

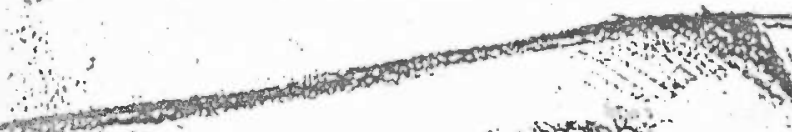

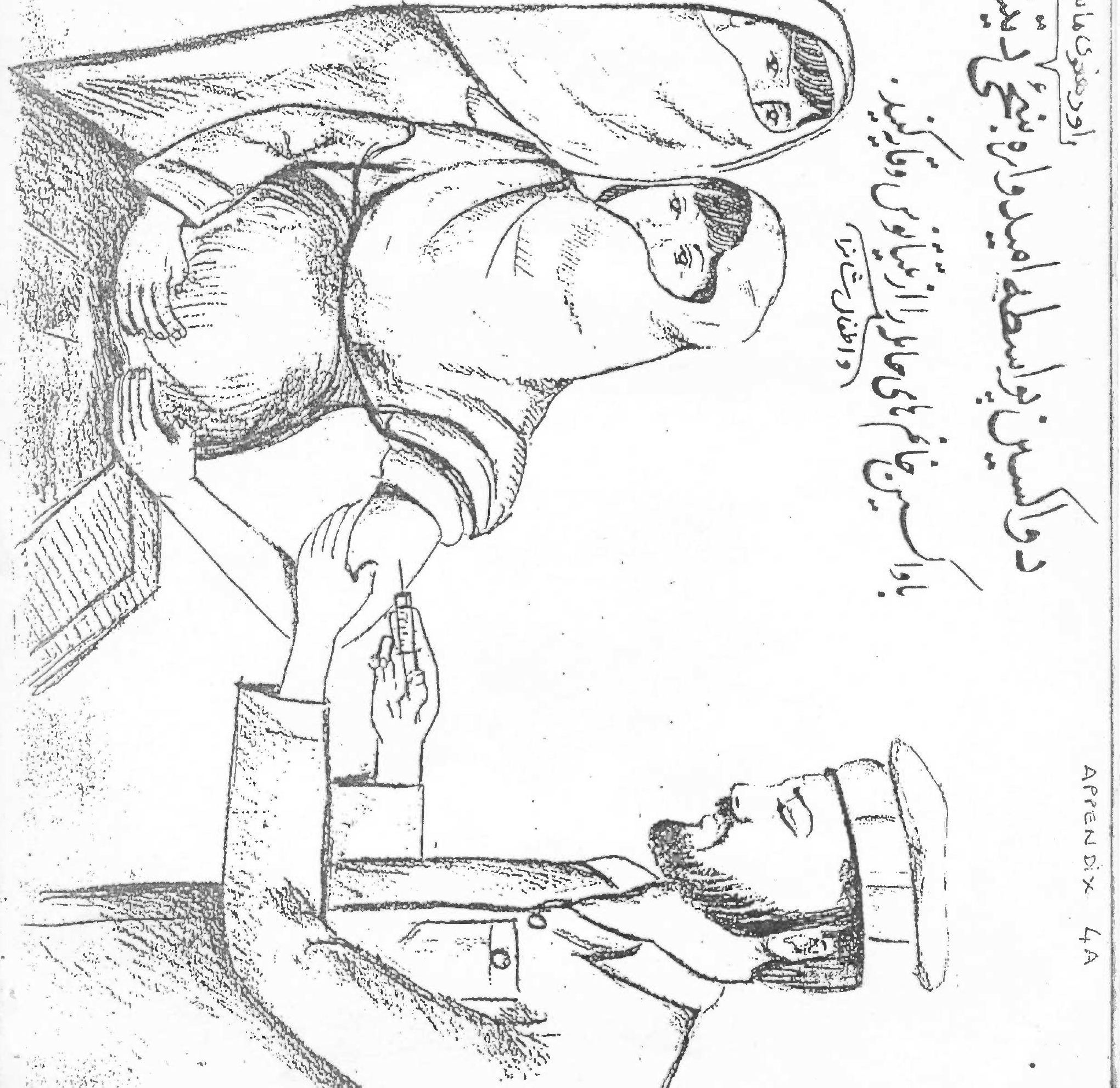




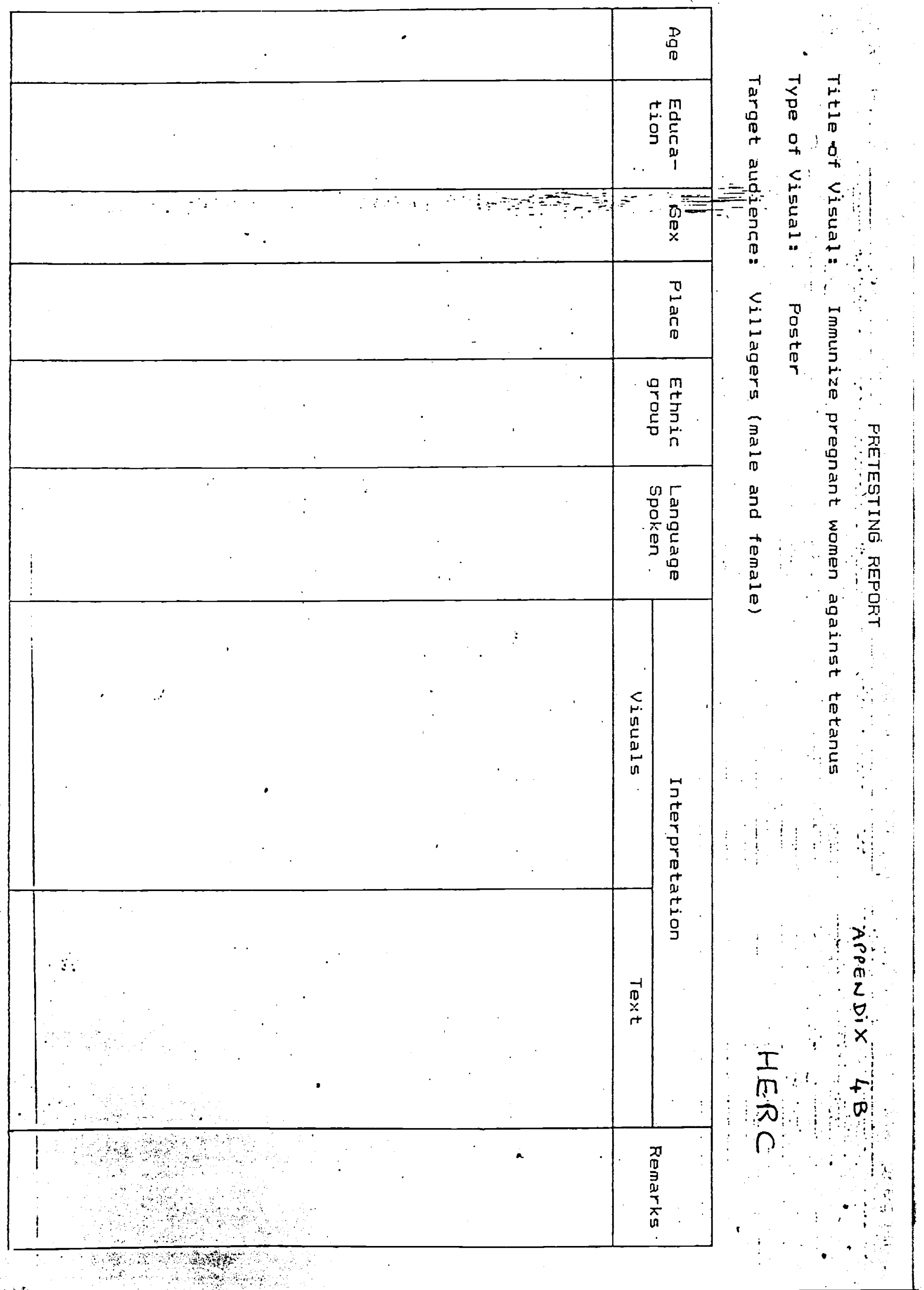




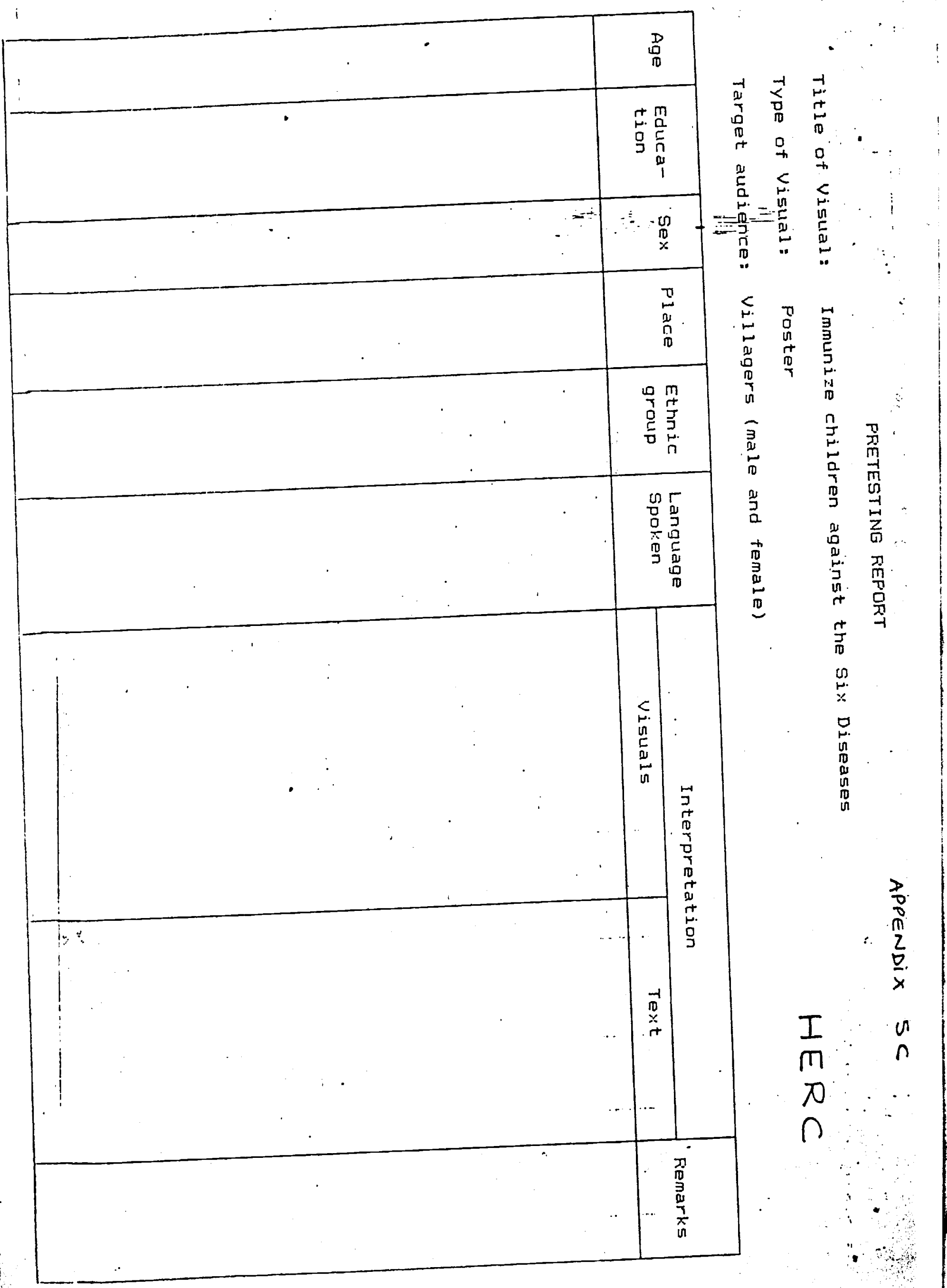

